\title{
Third Generation Antipsychotic as add-on therapy in Intractable Obsessive-Compulsive Disorder
}

\author{
Saeed Shoja Shafti* \\ Professor of Psychiatry, University of Social Welfare and Rehabilitation Sciences, Razi Psychiatric Hospital, Tehran, Iran
}

*Corresponding author: Saeed Shoja Shafti, Professor of Psychiatry, University of Social Welfare and Rehabilitation Sciences, Razi

Psychiatric Hospital, Tehran, Iran

\begin{tabular}{l}
\hline ARTICLE INFO \\
Received: 幽 April 16, 2019 \\
Published: ${ }^{ \pm}$April 26, 2019 \\
Citation: Saeed Shoja Shafti. Third Gen- \\
eration Antipsychotic as add-on ther- \\
apy in Intractable Obsessive-Compul- \\
sive Disorder. Biomed J Sci \& Tech Res \\
17(3)-2019. BJSTR. MS.ID.003016.
\end{tabular}

Abbreviations: NICE: National Institute for Health and Clinical Excellence; OCD: Obsessive- Compulsive Disorder; CBT: Cognitive Behavior Therapy; SRIs: Serotonin-Reuptake Inhibitors; SSRIs: Selective Serotonin Reuptake Inhibitors; SGAs: Second Generation Antipsychotics; EPS: Extrapyramidal Symptoms; SAS: Simpson - Angus Scale; AIMS: Abnormal Involuntary Movement Scale; YBOCS: Yale-Brown Obsessive Compulsive Scale; CGI-S: Clinical Global Impressions-Severity Scale; ES: Effect Size

\section{ABSTRACT}

Background: As is renowned, serotonin-reuptake inhibitors are ineffective in controlling of forty to sixty percent of patients suffering from obsessive-compulsive disorder. So, objective of the present appraisal was to measure that whether aripiprazole, as add-on to current treatment, is helpful in cases with intractable obsessive-compulsive disorder.

Method: In an open-label study with blinded rating, sixteen patients with OCD, who had not improved noticeably by serotonin-reuptake inhibitors, after maximum dosage and period, were allocated to get aripiprazole plus their SRIs for eight weeks. Management outcome had been assessed by Yale-Brown Obsessive Compulsive Scale (YBOCS). Complete reaction to the aforementioned add-on therapy had been defined of at least fifty percent reduction in YBOCS' score and partial reaction, as well, as equivalent to or $>25 \%-<50 \%$ reduction in YBOCS in comparison with the reference point.

Results: Neither of cases responded with at least 25\% decrease in YBOCS score to the added aripiprazole (20 mg/day). Eighteen percent of cases experienced a lessening between $10-20 \%$ and $68 \%$ of them less than $10 \%$. Two patients did not display any alteration at all. The mean+/-SD baseline YBOCS' score of 35.2 +/- 2.9 dropped to a mean of 32.8 $+/-4.1$ at endpoint with a mean reduction of $8.8+/-7.8 \%(\mathrm{p}<0.06)$.

Conclusion: Findings of the present assessment could not provide extra proof in favor of aripiprazole as add-on therapy in treatment-resistant OCD.

Keywords: Antipsychotic; Aripiprazole; Obsessive-Compulsive Disorder; Treatment Resistant

\section{Introduction}

According to the guidance of National Institute for Health and Clinical Excellence (NICE) respecting management of obsessivecompulsive disorder (OCD), and based on a 'stepped care' approach, though psychological therapy, like intensive cognitive behavior therapy (CBT), is more effective than pharmacological therapy and should be used as first line where possible, pharmacological therapy is also effective. In this regard, most evidence supports the use of the SSRIs, which in combination with the aforesaid psychological methods can be considered in refractory cases. Also, when there is moderate or severe functional impairment, and response to combination therapy is still suboptimal, addition of an antipsychotic can be tried [1]. In this regard, though serotoninreuptake inhibitors (SRIs) are known as the best effective medical management for obsessive-compulsive disorder, as many as fifty percent of OCD patients who have received an adequate trial of SRIs don't show suitable response to medical management and exhibit persistently remarkable symptoms [2].

Disregard to antidepressant activity, SRIs like fluvoxamine, fluoxetine, sertraline, paroxetine, citalopram and clomipramine have been shown to be helpful against obsessive - compulsive symptoms $[3,4]$. But in any case, fifty to sixty percent of cases with obsessive and compulsive symptoms don't react palpably to a single trial of a serotonin reuptake inhibitor, and twenty to forty percent of patients with OCD don't react satisfactorily after several drug tryouts [2]. Additionally, though the selective serotonin reuptake inhibitors (SSRIs) are generally acknowledged as safe and 
well-tolerated medications, a proportion of patients does suffer unbearable adverse effects and cease treatment too early. Moreover no particular medication performing on diverse neurotransmitter systems has hitherto presented a complete effectiveness against OCD. Beneficial tactics in these resistant patients typically involve adjunctive treatments with, buspirone, clonazepam, lithium and tryptophan [3]. Nonetheless, the concluding outcomes with these maneuvers were not inspiring thus far and have remained rather investigational than fundamental.

According to a series of large meta analyses or systematic reviews, a well-documented policy for treatment-resistant OCD is the adding of antipsychotic drugs to the current SRI treatment [5-7]. The adding of low dose antipsychotics to ordinary antidepressant medication has revealed to be helpful in some patients, but extrapyramidal adverse effects and reverse escalation of obsessive symptoms in some patients have restricted the use of conventional antipsychotics. Hence, management with atypical or second generation antipsychotics (SGAs) that displays rarer extrapyramidal signs could be an expedient alternate in treatmentresistant OCD. Incidentally, even though SGAs such as olanzapine or risperidone have been found useful in augmentation of serotonin reuptake inhibitors, they may well cause a quantity of health worries correlated with body weight or metabolic alterations [8-10]. But as regards aripiprazole, as newer SGAs, there are contradictory results in this regard [11-16].

While aripiprazole is a quinolinone derivative with a great empathy for D2, D3, 5-HT1A, 5-HT2A and 5-HT2B receptors, the mechanism of action of aripiprazole is not until now recognized [17]. Nevertheless, there is evidence that its effectiveness in the handling of the positive and negative symptoms of schizophrenia and its lesser tendency for extrapyramidal symptoms (EPS) may be attributable to aripiprazole's partial agonist activity at D2 receptors [17]. In the present assessment, the effectiveness and safety of aripiprazole as an adjunctive agent in treatment-resistant OCD have been investigated.

\section{Materials and Methods}

Eleven cases amongst clients of two psychiatric treatment centers, and five patients, who had been hospitalized in a psychiatric hospital, after complete description of the method for them and attaining signed cognizant permission, went into an Open-prospective, single-arm interventional study with blinded rating. The duration of trial, as well, was eight weeks and Academia's Therapeutic Morals Commission had sanctioned the assessment. Participants' illness was identified as obsessive compulsive disorder according to the criteria of Diagnostic and Statistical Manual of mental disorders, $5^{\text {th }}$ edition (DSM-V) [18]. Patients with known co-morbidity, like mood, psychotic, substance, neurological and medical problems, had been excluded from the investigation. Inclusion criteria in this trial were: 1) OCD symptoms unaffected by SRIs at maximum dosage (300 mg for fluvoxamine, $250 \mathrm{mg}$ for clomipramine,200 mg for sertraline and lastly $60 \mathrm{mg}$ for fluoxetine), and sufficient period ( 8 weeks). 2) A minimum score of 25on the YBOCS [16]. The patients's mean +/- SD starting point (baseline) score on the YBOCS was $35.2+/-2.9$.
In the course of the evaluation, while the appraiser was uninformed regarding the prearranged add-on therapy, all cases took incessantly their existing SRIs at the extreme dosage throughout trial. Aripiprazole adding was started at a dosage of 5 mg daily and then augmented by $5 \mathrm{mg}$ increases in weekly visits, to the highest of $20 \mathrm{mg}$ by $4 \mathrm{th}$ week, and at that point this amount was held constant up to the closure of the evaluation. At this point it is mentionable that, in the course of other similar trials, the prescribed dosage of aripiprazole as adjunctive medication in treatment - resistant OCD was frequently around 10, 15 or 20 mg per day [11-16]. So, in the present assessment, as well, the maximum dose was restricted to twenty mg per day. Moreover, for exclusion of confounding variables and measurement of just the effectiveness of augmentative drug, no other psychotropic prescription or psychosocial intervention (like CBT or Exposure Response Prevention) was administrated for them in the course of assessment. Yale-Brown Obsessive Compulsive Scale (YBOCS) was the main outcome measure in the present trial [19].

Clinical Global Impressions-Severity Scale (CGI-S), as well, was used as the ancillary scale [20]. Complete reaction to medical management was determined of at least fifty percent reduction in YBOCS' score and partial reaction as equivalent to or $>25 \%-<50 \%$ reduction in YBOCS' score in comparison with the starting point (baseline). Length of the study was eight weeks, and the participants were evaluated using YBOCS at week zero (baseline), $4^{\text {th }}$ week and $8^{\text {th }}$ week. CGI-S was recorded at the starting point and at the end of the study. The evaluator, an expert psychiatrist, was uninformed (blind) with respect to the aforesaid prescription and its objectives. Adverse events were appraised at every visit via patients' own reports and medical checkup by an additional psychiatrist, to keep the evaluation blind.

\section{Statistical Analysis}

Effectiveness of treatment was analyzed by t test and repeated -measures analysis of variance (ANOVA) comparing mean total score of YBOCS over eight weeks. Statistical significance was determined as a p value $<$ or $=$ to 0.05 . Cohen's Standard (d) and Correlation measures of effect size(r) were used for comparing baseline to end-point changes in primary outcome measure. Posthoc power analysis, as well, had been calculated with respect to assessment. MedCalc Statistical Software version 15.2 was used as arithmetical software instrument for analysis.

\section{Results}

The mean +/- SD age of the subjects was $34.7+/-7.7$ years, and the mean duration of illness was 7.3+/-3.4 years. Besides, all of them remained in the experiment up to its closing stages. Among participants, $63 \%$ were female $(n=10)$ and $37 \%$ were male $(n=6)$. According to the findings, no full or partial response (based on the abovementioned definitions) was evident in any of the cases (Figure 1). The mean+/-SD baseline YBOCS score of $35.2+/-2.9$ dropped to $32.8+/-4.1$ at endpoint (week 8 ) with a mean reduction of $8.8+/-7.8 \%$, which was not significant $(\mathrm{p}<0.06)$ (Figure 2$)$. Three patients $(18 \%)$ experienced some reduction between $10-20 \%$, and 11 patients $(68 \%)$ less than $10 \%$. On the other hand, two patients 
did not show any change at all. In those who earned benefit from the medical management, amelioration took place within the first two weeks of addition of adjunctive aripiprazole. Moreover, repeatedmeasures analysis of variance (ANOVA) as regards YBOCS, did not display any substantial alleviation by means of aeipiprazole at 8th week in comparison with starting point $[F(2,45)=2.30 p<0.11$ $\mathrm{SS}=32.38 \mathrm{MSe}=7.04]$.

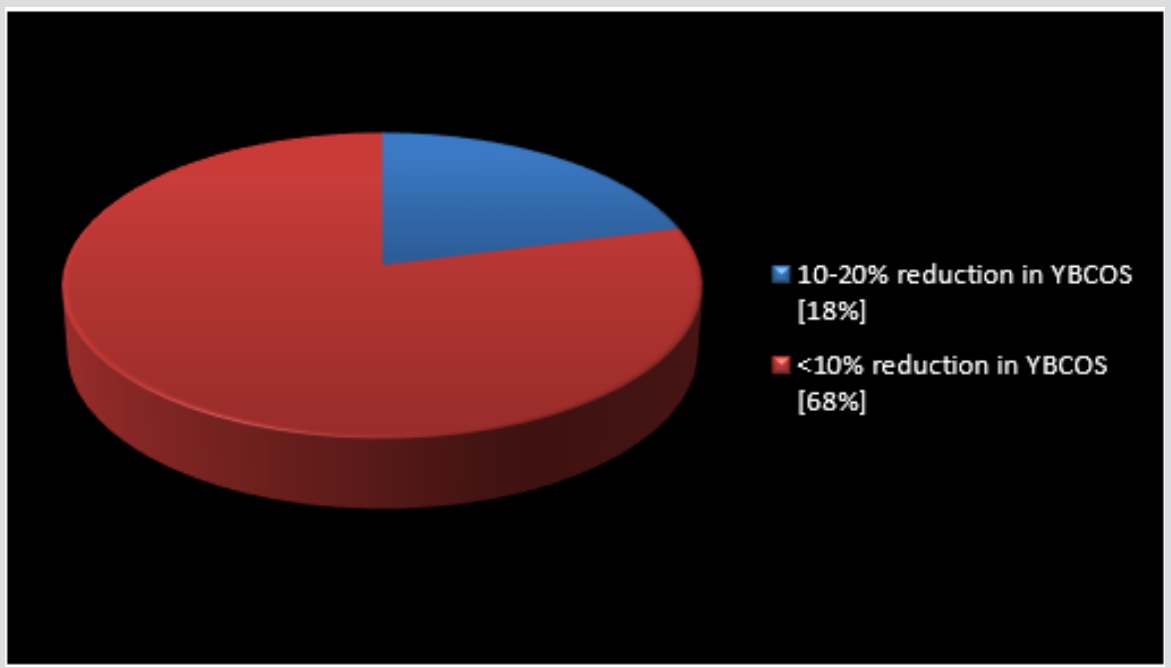

Figure 1: Overall response to add-on medication..

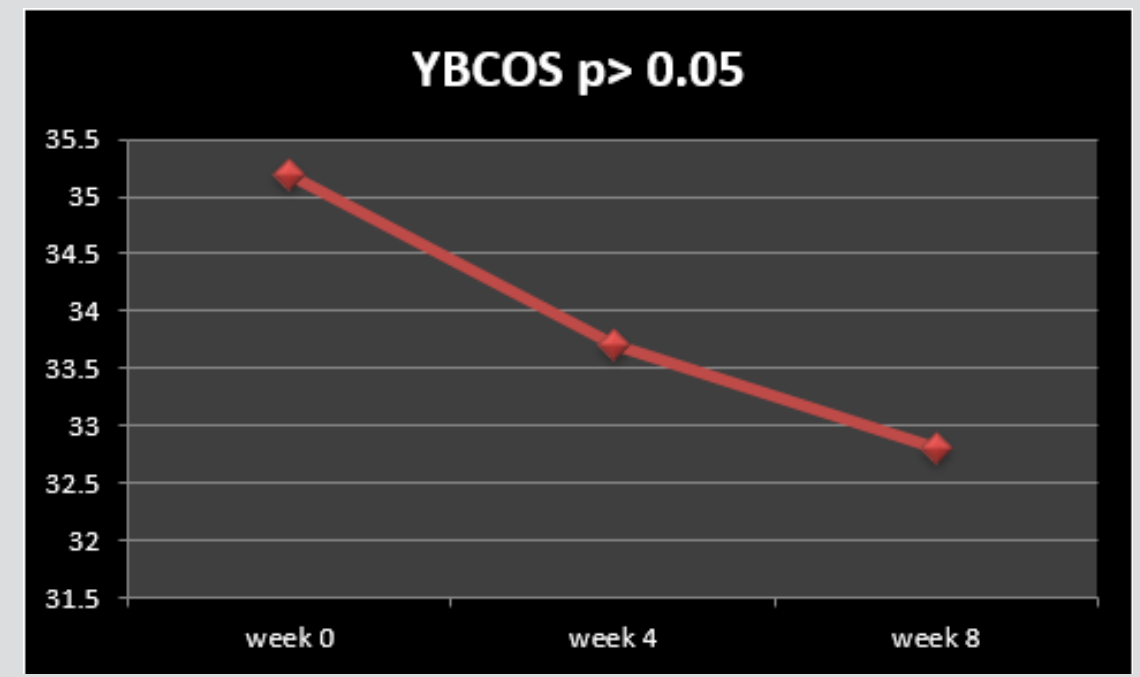

Figure 2: Changes of Outcome measure between baseline and week 8 .

Pair wise comparisons, as well, was not significant respecting head to head analysis of week 0 vs week 4 [ $t(30)=1.17, \mathrm{p}<0.24]$, week 4 vs week $8[\mathrm{t}(30)=0.613, \mathrm{p}<0.54]$, and lastly week 0 vs week $8[\mathrm{t}(30)=\mathrm{t}=1.95, \mathrm{p}<0.07]$. Also, with respect to mean total score of CGI-S in week 8, in comparison with baseline, no important alteration was obvious $(3.17+/-0.86$ to $3.12+/-1.16$; $\mathrm{t}=0.13, \mathrm{p}<$ 0.89). Since the sample size was small, the Effect size (ES) was explored for alterations on the YBOCS at the end of the tryout. The related outcome showed an intermediate enhancement of YBOCS by aripiprazole (Cohen's $d=0.67$, effect-size $r=0.32$ ). Post-hoc power analysis showed a power equal to 0.39 (somewhat intermediary) on behalf of this trial, which turned to power $=0.75$ in compromise power analysis. The most common adverse effects of aripiprazole among the participants, in the course of assessment, were inner unrest $(n=5)$, dizziness $(n=2)$, somnolence $(n=4)$, and mild stiffness ( $n=4$, which resolved with $3-6 \mathrm{mg} /$ day trihexyphenidyl). Since the adverse effects were slight and bearable, no one dropped out due to intolerance of prescribed adjunctive drug.

\section{Discussion}

Obsessive-compulsive disorder (OCD) is in essence an enduring malady with unpredictable outcome. On the other hand, while serotonin reuptake inhibitors (SRIs) are a known treatment for obsessive-compulsive disorder (OCD), approximately a third of patients does not respond to SRIs and remain chronically affected. So, since failure in its treatment is common, finding 
effective augmentations in treatment of OCD will benefit patients. Antipsychotic augmentation is a common strategy for treatment resistant OCD. For that reason, the evaluation of additive treatment in the presence of treatment resistance has high clinical relevance. In contrast, the present tryout did not bring complementary proof that addition of aripiprazole to current SRI treatment may be meaningfully effective for patients with therapy-resistant OCD. In all, the results of our study are not consistent with the findings of some of the previous trials with aripiprazole, like Sayyah M et al. [11], Higuma $\mathrm{H}$ et al. [12], and Matsunaga $\mathrm{H}$ et al. [13].

In this regard, while Sayyah $\mathrm{M}$ et al. and Higuma $\mathrm{H}$ et al. had found a significant reduction in total scores of YBOCS in the aripiprazole group by $10 \mathrm{mg} /$ day in a double-blind randomized clinical trial [11,12], and 3-12 mg/day in an Open - label tryout [13], respectively, higher doses of aripiprazole in the present assessment ( $20 \mathrm{mg} /$ day) could not demonstrate the same effectiveness. In addition, while Matsunaga $\mathrm{H}$ et al. [13] and Pessina $\mathrm{E}$ et al. [14] found in their Open label study that aripiprazole exhibited significant reduction of YBOCS (>35\%) in $70 \%$ and $66 \%$ of their samples, respectively, when added to ongoing SSRIs, our sample did not show more that $20 \%$ improvement in any of the cases. On the contrary, our result was partly consistent with the finding of Dold $\mathrm{M}$ et al. [5], who had found in his survey regarding efficacy of antipsychotics in treatment-resistant OCD that substantial effectiveness was distinguishable merely for risperidone, but not on behalf of olanzapine and quetiapine, and with unpredictable outcomes as regards haloperidol and aripiprazole.

By the way, Selvi $\mathrm{Y}$ et al., too, had found once more that risperidone might be more helpful than aripiprazole, in a singleblind add-on study respecting refractory OCD [15], a finding similar to the result of another comparative study that had found nonsignificant improvement by aripiprazole, while it was significant in response to quetiapine [16]. Regarding side effects, our results were somehow similar to Higuma $\mathrm{H}$ et al, who had found that many patients in their samples needed to take antiparkinsonian drugs to control extrapyramidal symptoms, as like as $25 \%$ of cases in the current assessment. But the prevalenece of inner unrest, which was reported by Pessina E et al. in $44.4 \%$ of their cases, was relatively lower in our experiment (31\%). The main problem here is that there is not hitherto any widespread agreement on the meaning of flexibility or inflexibility in the realm of management of OCD in comparison with, for example, schizophrenia. For example, Weiss et al. [9] defined a minimum limit of fifty percent reduction in YBOCS' score as responders, while Francobanderia [21] selected a limit of twenty five percent.

On the other hand, McDougle et al. [8] selected a further limiting norm with a cutoff of thirty five percent for YBOCS' reduction and a final score of sixteen on YBOCS in combination with an ultimate Clinical Global Impressions scale rating of much improved or very much improved. Denys D et al, as well, chose $>$ or $=50 \%$ decrease in YBOCS as full response, and $>$ or $=25 \%$ decrease in YBOCS from the beginning as partial response, in their study on quetiapine, as an augmentative agent [22]. There is some contradiction, as well, in the meaning of treatment - refractoriness. Most trials involved cases who had failed to respond to merely one SRI tryout. So, they should rather be qualified as treatment resistant. Only patients included in the study by Koren et al. [10] were truly treatment refractory, as they failed to respond to at least 3 adequate SRI treatments [23]. Such differences invalidate, unfortunately, the comparison of effect sizes between studies. So maybe, less strict inclusion criteria in the present assessment might result in a better outcome, as like as more duration of assessment or higher dosage of the augmentative agent.

Small sample size and consequently a power that could not be satisfactorily strong, short duration of assessment, single - label design, lack of clinical drug monitoring and also lack of standard scales, like Simpson - Angus Scale (SAS) or Abnormal Involuntary Movement Scale (AIMS) for measurement of extrapyramidal effects, were among the weak points of this study. Undoubtedly, Well-powered, prospective, randomized placebo-controlled trials are necessary to elucidate aripiprazole's safety and effectiveness as an adjunctive treatment in treatment-resistant OCD.

\section{Conclusion}

Findings of the present assessment could not provide extra proof in favor of aripiprazole as add-on therapy in treatmentresistant OCD.

\section{Acknowledgment}

The author appreciatively acknowledges dear colleagues, Hashemzadeh J (MD) and Dadvar P (PhD) for their valuable support.

\section{References}

1. (2005) National Institute for Health and Clinical Excellence. Obsessivecompulsive disorder: core interventions in the treatment of obsessivecompulsive disorder and body dysmorphic disorder. Clinical Guidance, p. 31.

2. Fienberg NA, Bullock T, Montgomery DB, Montgomery SA (1992) Serotonin reuptake inhibitors are the treatment of choice in obsessivecompulsive disorder. Clin Psychopharmacol 7(suppl 1): 43-47.

3. Mcdougle CJ, Gordman WK, Price LH (1993) The pharmacotherapy of obsessive-compulsive disorder. Pharmopsychiatry 269(suppl): 24-29.

4. Hollander E, Kaplan A, Allen A, Cartwright C (2000) Pharmacotherapy for obsessive-compulsive disorder. Psychiatric Clin North AM 23(3): 643-656.

5. Dold M, Aigner M, Lanzenberger R, Kasper S (2013) Antipsychotic augmentation of serotonin reuptake inhibitors in treatment-resistant obsessive-compulsive disorder: a meta-analysis of double-blind, randomized, placebo-controlled trials. Int J Neuropsychopharmacol 16(3): 557-574

6. Dold M, Aigner M, Lanzenberger R, Kasper S (2011) Efficacy of antipsychotic augmentation therapy in treatment-resistant obsessivecompulsive disorder: A meta-analysis of double-blind, randomised, placebo-controlled trials. Fortschr Neurol Psychiatr 79(8): 453-466.

7. Bloch $\mathrm{MH}$, Landeros Weisenberger A, Kelmendi B, Coric V, Bracken $\mathrm{MB}$, et al. (2006) A systematic review: antipsychotic augmentation with treatment refractory obsessive-compulsive disorder. Mol Psychiat 11(7): 622-632.

8. Mc Dougle CJ, Epperson CN, Pelton GH, Wasylink S, Price LH (2000) A double-blind, placebo-controlled study of resperidone addition in serotonin reuptake inhibitor-refractory obsessive-compulsive disorder. Arch Gen Psychiat 57(8): 794-801. 
9. Weiss El, Potenza MN, McDougle CJ, Epperson CN (1999) Olanzapine addition in obsessive-compulsive disorder refractory to selective serotonin reuptake inhibitors; an open-label case series. J Clin Psychiat 60: 524-527.

10. Koran LM, Ringold AL, Elliot MA (2000) Olanzapine augmentation for treatment-resistant obsessive-compulsive disorder. J Clin Psychiat 61(7): 514-517.

11. Sayyah M, Sayyah M, Boostani H, Ghaffari SM, Hoseini A (2012) Effects of aripiprazole augmentation in treatment-resistant obsessive-compulsive disorder (a double blind clinical trial). Depress Anxiety 29(10): 850-854.

12. Higuma H, Kanehisa M, Maruyama Y, Ishitobi Y, Tanaka Y, et al. (2012) Aripiprazole augmentation in 13 patients with refractory obsessivecompulsive disorder: A case series. World J Biol Psychiat 13(1): 14-21.

13. Matsunaga H, Hayashida K, Maebayashi K, Mito H, Kiriike N (2011) A case series of aripiprazole augmentation of selective serotonin reuptake inhibitors in treatment-refractory obsessive compulsive disorder. Int Psychiat Clin Pract 15(4): 263-269.

14. Pessina E, Albert U, Bogetto F, Maina G (2009) Aripiprazole augmentation of serotonin reuptake inhibitors in treatment-resistant obsessivecompulsive disorder: a 12-week open-label preliminary study. Int Clin Psychopharmacol 24(5): 265-269.

15. Selvi Y, Atli A, Aydin A, Besiroglu L, Ozdemir P, et al. (2011) The comparison of aripiprazole and risperidone augmentation in selective serotonin reuptake inhibitor-refractory obsessivecompulsive disorder: a single-blind, randomised study. Hum Psychopharmacol 26(1): 51-57.

\section{ISSN: 2574-1241}

DOI: 10.26717/BJSTR.2019.17.003016

Saeed Shoja Shafti. Biomed J Sci \& Tech Res

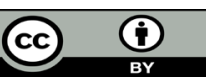

This work is licensed under Creative Commons Attribution 4.0 License

Submission Link: https://biomedres.us/submit-manuscript.php
16. Shoja Shafti S, Kaviani H (2015) Aripiprazole versus quetiapine in treatment resistant obsessive-compulsive disorder: A double-blind clinical trial. Ther Adv Psychopharmacol 5(1): 32-37.

17. Swainston Harrison T, Perry CM (2004) Aripiprazole: A review of its use in schizophrenia and schizoaffective disorder. Drugs 64(15): 1715-1736.

18. (2013) American Psychiatric Association (APA). Diagnostic and Statistical Manual of Mental Disorders. ( $5^{\text {th }}$ edn.). Washington, DC: American Psychiatric Association, pp. 671-672.

19. Goodman WK, Price LH, Rasmussen SA, Mazure C, Fleischmann RL, et al. (1989) The yale-brown obsessive compulsive scale, 1: development, use, and reliability. Arch Gen Psychiat 46(11): 1006-1011.

20. (1976) Clinical Global Impressions, ECDEU Assessment manual for psychopharmacology, Guy W, ed, Rockville: U.S. Department of Health, Education, and Welfare, 1976, DHEW Publication NO. (ADM), pp. 76-338.

21. Francobandiera G (2001) Olanzapine augmentation of serotonin uptake inhibitors in obsessive-compulsive disorder: an open study. Can J Psychiat 46(4): 356-358.

22. Denys D, Megan H, Westenberg H (2002) quetiapine addition Ti serotonin reuptake inhibitor Treatment in patients with treatment refractory obsessive-compulsive Disorder: An open -label study. J Clin Psychiat 63: 700-703.

23. Bystrisky A (2001) Augmentation of SSRI response in refractory OCD using adjunct olanzapine: a placebo-controlled trial. In New Research Abstracts of the $154^{\text {th }}$ Annual Meeting of the American Psychiatric Association.

$\begin{array}{ll}\text { BIOMEDICAL } & \text { Assets of Publishing with us } \\ \text { RESEARCHES } & \text { - Global archiving of articles } \\ \text { ISSN: } 2574-1241 & \text { - Immediate, unrestricted online access } \\ \end{array}$

